\title{
Research Paper: The Mediating Role of Alexithymia in the Relationship Between Defense Mechanisms and Tendency to High-risk Behaviors Among Adolescents
}

\author{
Zahra Nikmanesh $^{1^{*}}$ (D), Mehdi Darvish Molla ${ }^{1}$ (D), Mehrnosh Mehranfard ${ }^{1}$ (D) \\ 1. Department of Education, Faculty of Education and Psychology, University of Sistan and Baluchestan, Zahedan, Iran.
}

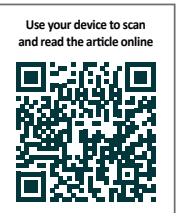

Citation Nikmanesh Z, Darvish Molla M, Mehranfard M. The Mediating Role of Alexithymia in the Relationship between Defense Mechanisms and Tendency to High-risk Behaviors among Adolescents. Journal of Health Research. 2021; 11(1):29-36. http://dx.doi.org/10.32598/JRH.11.1.363.6

dof : http://dx.doi.org/10.32598/JRH.11.1.363.6

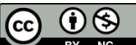

Article info:

Received: 17 Jan 2018

Accepted: 23 Nov 2018

Publish: 01 Feb 2021

\section{Keywords:}

Affective symptoms, Defense mechanisms, Risk-taking, Adolescent

\section{ABSTRACT}

Background: Although high-risk behaviors lead to adverse physical, psychological, and sociological consequences, less attention has been paid to identifying their related factors. The aim of this study was to investigate the mediating role of alexithymia in the relationship between defense mechanisms and high-risk behaviors among adolescents in Zahedan.

Methods: In this descriptive-correlative study, junior and senior high school students of Zahedan, Iran were studied in the academic year 2015-2016. A sample of 250 (125 males and 125 females) students were chosen by multi-stage cluster sampling and asked to complete the Defense Style Questionnaire (DSQ), Toronto Alexithymia Scale (TAS), and the Risk-Taking Scale (IARS) for Iranian Adolescents. Data analysis was conducted by measuring coefficients of correlation and performing a path analysis.

Results: Path analysis showed a significant correlation between defense mechanisms and alexithymia $(\mathrm{P}<0.01)$ and a significant correlation was found between immature defense mechanisms and high-risk behaviors $(\mathrm{P}<0.01)$.

Conclusion: In the relationship between dysfunctional defense mechanisms and high-risk activities, alexithymia played a mediating role. It can be inferred that dysfunctional defense mechanisms play a key role in high-risk activities by influencing alexithymia.

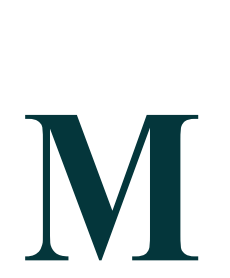

\section{Introduction}

any high-risk behaviors, such as highrisk sexual behaviors and cigarette smoking, alcohol use, and substance abuse usually begin in adolescence [1]. Therefore, alcohol abuse is highly ob- served in this age group [2]. Defense mechanisms can be listed among factors that affect the incidence of highrisk behaviors. Mechanisms of defense play a key role in substance [3] and alcohol [4] abuse.

Defense mechanisms are automatic psychological processes, which minimize cognitive dissonance by dis-

* Corresponding Author:

Zahra Nikmanesh, PhD.

Address: Department of Psychology, Faculty of Education and Psychology, University of Sistan \& Baluchestan, Zahedan, Iran.

Phone: +98 (915) 1404553

E-mail:nikmanesh@ped.usb.ac.ir 
torting the perceptions of threatening events and minimizing sudden changes in internal and external realities [5]. Such mechanisms include mechanisms for mature, immature, and neurotic defense [6]. Effective defense mechanisms enhance mental health and inefficient defense mechanisms result in several mental disorders, such as depression [6]. There have been significant differences in defense mechanisms between addicts and non-addicts so that non-addicts have more mature defense mechanisms compared with addicts $[3,7]$.

Costa and Brody reported that only immature defense mechanisms were directly related to alcohol abuse between defense mechanisms [8], while Brody and Carson [9] concluded that immature defense mechanisms were positively correlated with self-harm and were not significantly related to alcohol and substance abuse. The results of a study conducted on people with depression showed that patients who committed suicide had higher scores regarding immature defense mechanisms compared with others [10].

Because defense mechanisms modify and change subconscious emotional experiences without being consciously accessible $[11,12]$, alexithymia is one of the consequences of the lack of mature defense mechanisms [13]. Therefore, defense mechanisms play a decisive role in alexithymia.

Alexithymia is characterized by an inability to regulate cognitive processing and emotion [14]. Numerous mental disorders, such as anxiety or obsessive-compulsive disorder are correlated with alexithymia [15-17]. Alexithymia is associated with defense mechanisms [15-17] so that it is correlated with mature defense mechanisms and is directly associated with mechanisms of immature and neurotic defense [18]. Bogutyn et al. [19] concluded that alexithymia was only positively related to immature defense mechanisms and it was not significantly correlated with other defense mechanisms. Similarly, Helmes et al. [20] found that alexithymia was only correlated with immature defense mechanisms.

Emotions and the way, in which they are regulated play a key role in the incident of high-risk behaviors [21-24] so that the lack of emotional regulation and alexithymia were directly related to excessive alcohol abuse [25]. Alexithymia is also a strong predictor of high-risk sexual behaviors and there is an association between alexithymia and drug abuse [26]. Although the results of a number of previous studies indicated a positive relationship between alexithymia and alcohol dependence, in their meta-analysis, Thorberg et al. [27] provided limited evidence regarding the relationship between alexithymia and alcohol abuse and severity of dependence. Therefore, further studies are needed to study the relationship between defense mechanisms, alexithymia, and highrisk behaviors among adolescents.

Given the significance of adolescence as a critical period of development and considering the significant high-risk behaviors that affect adolescents, it is important to conduct a study to analyze their risk factors. Because difficulties in controlling emotions, and immature mechanisms of defense are predictors of substance abuse [28], this study sought to answer the following question: is alexithymia a mechanism, through which defense mechanisms affect the incidence of high-risk behaviors among adolescents? The current study was done to assess the mediating role of alexithymia in the relationship between defense mechanisms and high-risk behaviors in adolescents in Zahedan.

\section{Methods}

This descriptive study followed a correlational design. The statistical population included all junior and senior high school students in Zahedan in the academic year 2015-2016. The sample size was 250 participants selected according to the Morgan table and using multistage cluster sampling. A list of all Zahedan high schools was prepared and several schools were then selected as a cluster and based on their grades, students were categorized. Then, 250 students (125 male students and 125 female students) were randomly selected in different grades and completed the questionnaires.

\section{Tools}

The Defense Style Questionnaire: Andrews et al. developed this questionnaire. It includes 40 items and is scored on a 9-point Likert-type scale, evaluating three defense mechanisms, including mature, neurotic, and immature defense mechanisms. Mature defense mechanisms include sublimation, humor, anticipation, and suppression. Mechanisms of neurotic defense include undoing, pseudo-altruism, idealization, and formation of reactions. Mechanisms of immature defense consist of projection passive aggression, acting out, alienation, devaluation, autistic fantasy denial, displacement dissociation, splitting, rationalization, and somatization. Besharat et al. [29] assessed the reliability and validity of the Persian version of this questionnaire and reported that Cronbach's alpha coefficients of the subscale, i.e. mature, neurotic, and immature defense mechanisms were $0.75,0.73$, and 0.72 , respectively. In addition, they showed the test-retest reliability of 0.81 for the questionnaire. Heidarinasab [30] 


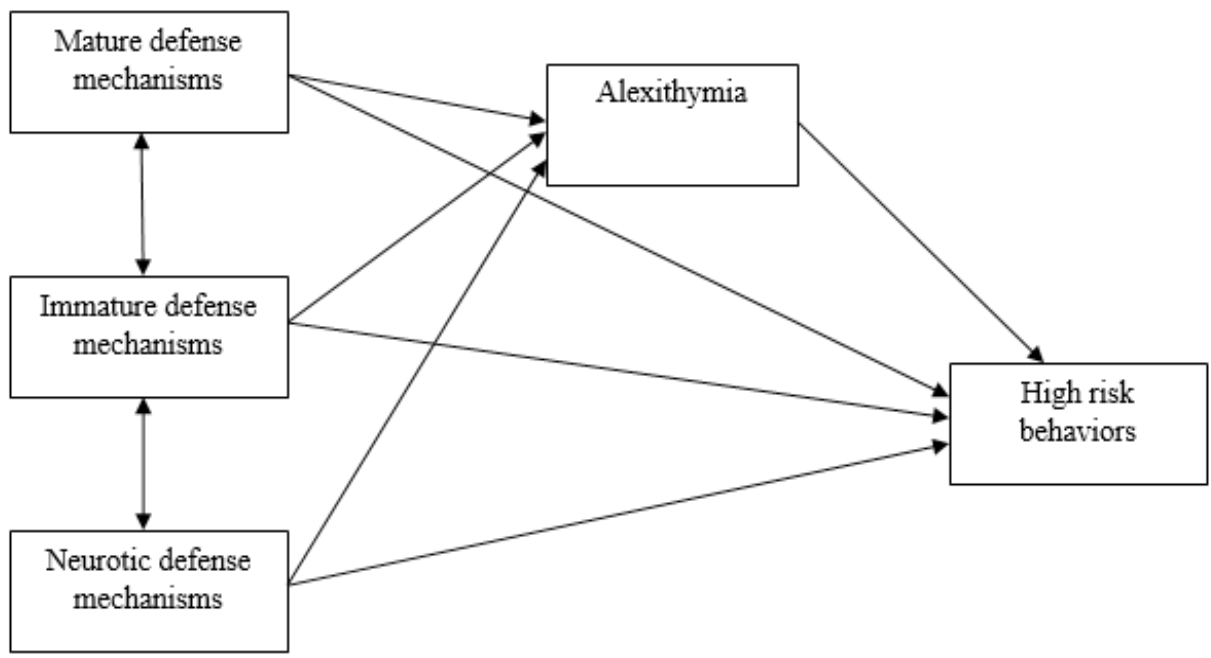

Figure 1. The Proposed Model

used the questionnaire in another study and administrated it on high school and university students. In the current study, the Cronbach's alpha coefficients of the three subscales of mature, neurotic, and immature defense mechanisms were $0.76,0.71$, and 0.82 , respectively.

The Toronto Alexithymia Scale: Bagby et al. developed this scale [31] with 20 items. It has three subscales, including difficulty in identifying feelings, difficulty in describing feelings, and externally-oriented thinking scored on a 5-point Likert-type scale ranging from total disagreement to complete agreement. The Toronto Alexithymia Scale-20 has been confirmed to be reliable and valid [32]. Cronbach's alpha coefficients of the whole scale and the three subscales of difficulty in identifying feelings, difficulty in describing feelings, and externally-oriented thinking were $0.85,0.82,0.75$, and 0.72 , respectively. In addition, this scale's test-retest reliability ranged from 0.80 to 0.87 [33]. Cronbach's alpha coefficient of this measure in the current study was 0.84 .

The Risk-Taking Scale for Iranian adolescents: 38 items and 7 subscales are included in this scale. Dangerous driving, violence, cigarette smoking, substance abuse, alcohol consumption, sexual behaviors and relationships, and opposite-sex friendships are the subscales of this scale [34]. Each item is scored based on a 5-point Likert-type scale (ranging from totally disagree to totally agree). Cronbach's alpha coefficients are 0.74 , $0.78,0.93,0.90,0.90,0.87,0.83$, and 0.72 , respectively for dangerous driving, violence cigarette smoking, substance abuse, alcohol consumption, and sexual behaviors and relationships [35]. In this study, Cronbach's alpha coefficient for the whole scale was 0.78 .

\section{Ethical Considerations}

All questionnaires were completed anonymously without disclosing any names or addresses in order to observe ethical considerations. All subjects completed informed consent. Data analyses: To analyze the obtained data, SPSS V. 22 and AMOS V. 22 were applied. The mean and standard deviation were used to analyze the descriptive characteristics of the research variables. Pearson correlation coefficient was used to analyze correlations between variables. Model fit indices, including Chi-square goodness-of-fit test (Chi-square/df), Root Mean Approximation Error (RMSEA), Goodness-of-Fit Index (GFI), Comparative Fit Index (CFI), and Normed Fit Index (NFI) were used to perform the path analysis $[36,37]$. In addition, a Bootstrap method was used to determine the mediating role of the considered variable.

\section{Results}

The mean age of the subjects was 14.51 years ranged 12-18. Descriptive statistics related to all the variables are presented in Table 1. Table 2 presents the Pearson correlation coefficients of variables. According to this table, mature defensive mechanisms were related to alexithymia in a significant and diverse manner. In contrast, immature defense mechanisms were correlated with alexithymia and high-risk behaviors significantly and directly. Neurotic defense mechanisms were not significantly correlated with alexithymia and high-risk behaviors.

The mediating role of alexithymia in the relationship between defense mechanisms and high-risk behaviors was assessed in adolescents in Zahedan. The model's standardized coefficients and indicators of significance 
Table 1. The descriptive statistics of the study variables

\begin{tabular}{cc}
\hline Variables & Mean \pm SD \\
\hline Mature defense mechanisms & $6.02 \pm 1.58$ \\
\hline Immature defense mechanisms & $5.21 \pm 1.36$ \\
Neurotic defense mechanisms & $4.57 \pm 1.32$ \\
High-risk behaviors & $3.22 \pm 0.91$ \\
Alexithymia & $43.90 \pm 11.46$ \\
\hline
\end{tabular}

SD: Standard Deviation.

Table 2. The correlation matrix among the study variables

\begin{tabular}{cccccc}
\hline Variables & $\mathbf{1}$ & $\mathbf{2}$ & $\mathbf{3}$ & $\mathbf{4}$ & $\mathbf{5}$ \\
\hline Mature defense mechanisms & 1 & & & \\
\hline Immature defense mechanisms & $-0.20^{* *}$ & 1 & & \\
\hline Neurotic defense mechanisms & $-0.17^{* *}$ & $0.22^{* *}$ & 1 & 1 & \\
High-risk behaviors & -0.06 & $0.39^{* *}$ & 0.09 & 0.08 & 1 \\
\hline Alexithymia & $-0.27^{* *}$ & $0.25^{* *}$ & 0.08 & \\
\hline
\end{tabular}

$* * \mathrm{P}<0.01$.

URA

of the whole model indicated that the theoretical model was significant. In other words, given the model fit indices $\left(\mathrm{X}^{2} / \mathrm{df}=1.84, \mathrm{RMSEA}=0.058, \mathrm{GFI}=0.991, \mathrm{NFI}=\right.$ 0.951 , and $\mathrm{CFI}=0.976$ ), the model was desirably significant. Additionally, defense mechanisms predict $11 \%$ of the variance of mechanisms of alexithymia, and defense and alexithymia together predicted $19 \%$ of the variance of high-risk behaviors. Figure 1 displays the standardized coefficients of the model.

The Bootstrap method was implemented using the Preacher and Hayes macro approach [38] to analyze the mediating role of the variables. The confidence interval of the studied path was $95 \%$ and the number of 5000 Bootstrap resampling was obtained from 0.0280 (lower limit) to 0.1774 (upper limit). Therefore, as 0 is not between the lower limit and the upper limit, alexithymia plays a therapeutic role in the relationship between defensive mechanisms and high-risk behaviors (Figure 2).

\section{Discussion}

Based on the results of the current study, mechanisms of immature defense played key roles in high-risk behaviors. This result is consistent with the findings of some previous studies $[4,9]$. Those who use immature defense mechanisms have poor levels of mental health [39], are unable to use effective defense mechanisms in stressful situations, and display destructive behaviors, such as substance abuse [3, 7]. Based on these results, there was no significant relationship between mature and neurotic defense mechanisms and high-risk behaviors. This result is consistent with other studies, in which mature and neurotic defense mechanisms were not related to alcohol abuse [8] or suicide [10].

The results of this study demonstrated an indirect relationship between defense mechanisms and high-risk behaviors among adolescents through alexithymia; thus, defense mechanisms played significant roles in alexithymia variance. Alexithymia also played a key role in improving high-risk behaviors. This suggests that by affecting alexithymia, inadequate defense mechanisms increased high-risk behaviors. To explain these results, it is important to note the role of defense mechanisms in modifying and adjusting unconscious emotional experiences $[11,12]$. Alexithymia is one of the consequences of the lack of mature mechanisms of defense [13]. It also raises a number of negative mental consequences (such as depression) [15-17]. People who use less mature mechanisms of defense and more immature mechanisms of defense experience high levels of alexithymia [18-20, 40]. In contrast, alexithymia plays a key role in high-risk behaviors, such as substance abuse [26], high- 


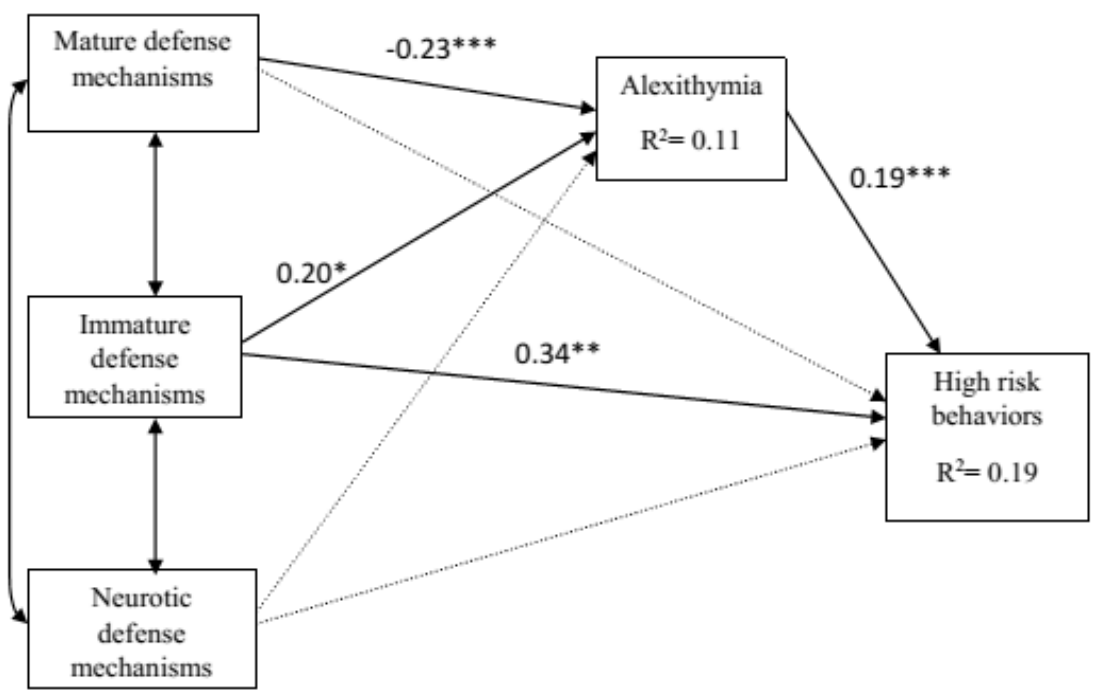

Figure 2. The effects of defense mechanisms on high-risk behaviors regarding the mediating role of alexithymia

The arrows indicate the significant paths, and the paths, which are not significant are illustrated with dashed arrows. The standardized coefficients related to the paths are presented on top of them $\left(\mathrm{X}^{2} / \mathrm{df}=1.84, \mathrm{RMSEA}=0.058, \mathrm{GFI}=0.991, \mathrm{NFI}=0.951\right.$, $\mathrm{CFI}=0.976 ;{ }^{*} \mathrm{P}<0.05 ; * * \mathrm{P}<0.01$; and $\left.{ }^{* * *} \mathrm{P}<0.001\right)$.

risk sexual behaviors [25], and alcohol dependence [25]. Based on previous studies $[8,18,19]$, immature defense mechanisms were more related to high-risk behaviors and alexithymia compared with other defense mechanisms. In this regard, the results of this research, suggesting that alexithymia also played a mediating role in the relationship between immature defense mechanisms and high-risk behaviors are accepted. Therefore, with an increase in inadequate defense mechanisms, alexithymia decreases, and with an increase in alexithymia, the possibility of high-risk behaviors can be increased.

Generally, considering the direct relationship between immature defense mechanisms and high-risk behaviors, as well as the mediating role of alexithymia in this relationship, it can be concluded that a part of the relationship between defense mechanisms and high-risk behaviors was mediated by alexithymia.

This study was cross-sectional research and the sample was limited to adolescents in Zahedan, which were the limitations of the current study. In addition, according to the results obtained from this study, immature defense mechanisms appeared to increase high-risk behaviors among adolescents due to the mediating role of alexithymia. It is therefore recommended that workshops be conducted on defense mechanisms and alexithymia to increase adolescents' and their parents' awareness.

\section{Conclusion}

Our findings indicated that adolescents' participation in risky behaviors can be predicted by alexithymia and defensive mechanisms. These findings highlight the importance of emotional regulation in children and the need for potential interventions and research for the prevention of such behaviors. However, increasing the awareness of adolescents regarding emotions and increasing their confidence in expressing feelings in appropriate ways can help protect them from various forms of risky behaviors.

\section{Ethical Considerations}

\section{Compliance with ethical guidelines}

This study was approved by Ethics Committee of University of Sistan and Baluchestan in Zahedan (Code: IR.USB.REC.1399.008).

\section{Funding}

This research did not receive any grant from funding agencies in the public, commercial, or non-profit sectors.

\section{Authors' contributions}

Study design: Zahra Nikmanesh, Mehrnosh Mehranfard; Data collection and data analysis: Mahdi Molladarvish, Mehrnosh Mehranfard; Manuscript preparation and editing: Zahra Nikmanesh, Mehdi Darvish Molla. 


\section{Conflict of interest}

The authors declare that they have no competing interests.

\section{References}

[1] Smith TME, Wessel MT. Alcohol, drugs, and links to sexua risk behaviors among a sample of Virginia college students. J Drug Educ. 2011; 41(1):1-16. [DOI:10.2190/DE.41.1.a] [PMID]

[2] Maggs JL, Schulenberg JE. Trajectories of alcohol use during the transition to adulthood. Alcohol Res Health. 2004 28(4):195-201. https://pubs.niaaa.nih.gov/publications/ arh284/195-201.pdf

[3] Bulik CM, Sullivan PF, Carter FA, Joyce PR. Lifetime comorbidity of alcohol dependence in women with bulimia nervosa. Addict Behav. 1997; 22(4):437-46. [DOI:10.1016/S03064603(96)00053-6]

[4] Pitkäned T. Problem drinking and psychological well-being: A five year follow-up study for adolescence to young adulthood.Scand J Psychol. 1999; 40(3):197-207. [DOI:10.1111/14679450.00117] [PMID]

[5] Vaillant GE. Ego mechanisms of defense: A guide for clinicans and researchers. Washington, DC: American Psychiatric Pub; 1992. https://www.amazon.com/Ego-Mechanism-Defense-Clinicians-Researchers/dp/0880484047

[6] Andrews G, Singh M, Bond M. The defense style questionnaire. J Nerv Ment Dis. 1993; 181(4):246-56. [DOI:10.1097/00005053-199304000-00006] [PMID]

[7] Ahmadi M, Najafi M, Hosseini Almadani A, Ashori A. [The comparison of defense mechanism styles and personality characteristics in addicts and healthy individuals (Persian)] Etiadpajohi. 2012; 6(23):39-51. http://etiadpajohi.ir/article1-317-fa.html

[8] Costa RM, Brody S. Immature psychological defense mechanisms are associated with greater personal importance of junk food, alcohol, and television. Psychiatry Res. 2013; 209(3):535-9. [DOI:10.1016/j.psychres.2013.06.035] [PMID]

[9] Brody S, Carson CM. Brief report: Self-harm is associated with immature defense mechanisms but not substance use in a nonclinical Scottish adolescent sample. J Adolesc. 2012 35(3):765-7. [DOI:10.1016/j.adolescence.2011.09.001] [PMID]

[10] Corruble E, Bronnec M, Falissard B, Hardy P. Defense styles in depressed suicide attempters. Psychiatry Clin Neurosci 2004; 58(3):285-8. [DOI:10.1111/j.1440-1819.2004.01233.x] [PMID]

[11] Cramer P, Brilliant MA. Defense use and defense understanding in children. J Pers. 2001; 69(2):297-322 [DOI:10.1111/1467-6494.00147] [PMID]

[12] Gross JJ, Thompson RA. Emotion regulation: Conceptual foundations. In: Gross JJ, editor. Handbook of emotion regulation. New York, NY, US: Guilford Press; 2007. https:/ / psycnet.apa.org/record/2007-01392-001
[13] Parker JD, Taylor GJ, Bagby RM. Alexithymia: Relationship with ego defense and coping styles. Compr Psychiatry. 1998; 39(2):91-8. [DOI:10.1016/S0010-440X(98)90084-0]

[14] Taylor GJ. Recent developments in alexithymia theory and research. Can J Psychiatry. 2000; 45(2):134-42. [DOI:10.1177/070 674370004500203] [PMID]

[15] Honkalampi K, Hintikka J, Tanskanen A, Lehtonen J, Viinamäki $\mathrm{H}$. Depression is strongly associated with alexithymia in the general population. J Psychosom Res. 2000; 48(1):99-104. [DOI:10.1016/S0022-3999(99)00083-5]

[16] Rufer M, Ziegler A, Alsleben H, Fricke S, Ortmann J, Brückner E, et al. A prospective long-term follow-up study of alexithymia in obsessive-compulsive disorder. Compr Psychiatry. 2006; 47(5):394-8. [DOI:10.1016/j.comppsych.2005.12.004] [PMID]

[17] Mattila AK, Kronholm E, Jula A, Salminen JK, Koivisto A-M, Mielonen R-L, et al. Alexithymia and somatization in general population. Psychosom Med. 2008; 70(6):716-22. [DOI:10.1097/ PSY.0b013e31816ffc39] [PMID]

[18] Kooiman CG, Spinhoven P, Trijsburg RW, Rooijmans HG Perceived parental attitude, alexithymia and defense style in psychiatric outpatients. Psychother Psychosom. 1998; 67(2):817. [DOI:10.1159/000012264] [PMID]

[19] Bogutyn T, Kokoszka A, Pałczyński J, Holas P. Defense mechanisms in alexithymia. Psychol Rep. 1999; 84(1):183-7. [DOI:10.2466/pr0.1999.84.1.183] [PMID]

[20] Helmes E, McNeill PD, Holden RR, Jackson C. The construct of alexithymia: Associations with defense mechanisms. J Clin Psychol. 2008; 64(3):318-31. [DOI:10.1002/jclp.20461] [PMID]

[21] Breslin FC, Zack M, McMain S. An information-processing analysis of mindfulness: Implications for relapse prevention in the treatment of substance abuse. Clin Psychol Sci Pract. 2002 9(3):275-99. [DOI:10.1093/clipsy.9.3.275]

[22] Nikmanesh Z, Kazemi Y, Khosravi M. Role of feeling of loneliness and emotion regulation difficulty on drug abuse. IJMTFM 2015; 5(4):185-91. [DOI:10.22037/ijmtfm.v5i4(Autumn).8744]

[23] Fox HC, Hong KA, Sinha R. Difficulties in emotion regulation and impulse control in recently abstinent alcoholics compared with social drinkers. Addict Behav. 2008; 33(2):388-94. [DOI:10.1016/j.addbeh.2007.10.002] [PMID]

[24] Berking M, Margraf M, Ebert D, Wupperman P, Hofmann SG, Junghanns K. Deficits in emotion-regulation skills predict alcohol use during and after cognitive-behavioral therapy for alcohol dependence. J Consult Clin Psychol. 2011; 79(3):307-18 [DOI:10.1037/a0023421] [PMID] [PMCID]

[25] Hahn AM, Simons RM, Simons JS. Childhood maltreatment and sexual risk taking: the mediating role of alexithymia. Arch Sex Behav. 2016; 45(1):53-62. [DOI:10.1007/s10508-015-0591-4] [PMID] [PMCID]

[26] Carton S, Bayard S, Paget V, Jouanne C, Varescon I, Edel Y, et al. Emotional awareness in substance-dependent patients. J Clin Psychol. 2010; 66(6):599-610. [DOI:10.1002/jclp.20662] [PMID]

[27] Thorberg FA, Young RM, Sullivan KA, Lyvers M. Alexithymia and alcohol use disorders: A critical review. Addict Behav. 2009; 34(3):237-45. [DOI:10.1016/j.addbeh.2008.10.016] [PMID] 
[28] Di Pierro R, Benzi IMA, Madeddu F. Difficulties in emotion regulation among inpatients with substance use disorders: the mediating effect of mature defenses mechanisms. Clin Neuropsychiatry. 2015; 12(4):83-9. https:// psycnet.apa.org/ record/2016-15888-001

[29] Besharat MA, Sharifi M, Irvani M. [Investigating the relationship between attachment and defense style (Persian)] Iran J Psychol . 2001; 5(3):277-89. https://www.sid.ir/fa/ Journal/ViewPaper.aspx?id=26675

[30] Heidarinasab L. [The comparison of defense mechanism in clinical and nonclinical samples based on psychometric norms and findings of Iranian defense mechanism styles questionnaire (Persian)] [PhD dissertation]. Tehran: Tarbiat Modares University; 2007.

[31] Bagby RM, Parker JD, Taylor GJ. The twenty-item Toronto Alexithymia Scale-I. Item selection and cross-validation of the factor structure. J Psychosom Res. 1994; 38(1):23-32. [DOI:10.1016/0022-3999(94)90005-1]

[32] Parker JDA, Taylor GJ, Bagby RM. The relationship between emotional intelligence and alexithymia. Pers Individ Dif. 2001; 30(1):107-15. [DOI:10.1016/S0191-8869(00)00014-3]

[33] Besharat MA. Reliability and factorial validity of a Farsi version of the 20-item Toronto Alexithymia Scale with a sample of Iranian students. Psychol Rep. 2007; 101(1):209-20. [DOI:10.2466/PR0.101.5.209-220] [PMID]

[34] Zadehmohammadi A, Ahmadabadi Z, Panaaghi L, Heidari M. [Construction and norm seeking of the seal of the young's risk-taking (Persian)]. Iran J Psychiatry \& Clin Psychol. 2011; 15(2):130-46. https://www.sid.ir/fa/journal/ViewPaper. aspx?id=151868

[35] Zadehmohammadi A, Ahmadabadi Z, Heidari M. [Construction and assessment of psychometric features of Iranian adolescents' risk-taking scale (Persian)]. Iran J Psychiatry Clin Psychol. 2011; 17(3):218-25. http://ijpcp.iums.ac.ir/article1-1417-en.html

[36] Hu L-t, Bentler PM. Cutoff criteria for fit indexes in covariance structure analysis: Conventional criteria versus new alternatives. Struct Equ Modeling. 1999; 6(1):1-55. [DOI:10.1080/10705519909540118]

[37] Schermelleh-Engel K, Moosbrugger H, Müller H. Evaluating the fit of structural equation models: Tests of significance and descriptive goodness-of-fit measures. Methods Psychol Res Online. 2003; 8(2):23-74. https://psycnet.apa.org/record/2003-08119-003

[38] Preacher KJ, Hayes AF. Asymptotic and resampling strategies for assessing and comparing indirect effects in multiple mediator models. Behav Res Methods. 2008; 40(3):879-91. [DOI:10.3758/BRM.40.3.879] [PMID]

[39] Bond M, Perry JC. Long-term changes in defense styles with psychodynamic psychotherapy for depressive, anxiety, and personality disorders. Am J Psychiatry. 2004; 161(9):1665-71. [DOI:10.1176/appi.ajp.161.9.1665] [PMID]

[40] Besharat MA, Shahidi S. What is the relationship between alexithymia and ego defense styles? A correlational study with Iranian students. Asian J Psychiatr. 2011; 4(2):145-9. [DOI:10.1016/j.ajp.2011.05.011] [PMID] 
This Page Intentionally Left Blank 